A Journal of Culture, English Language, Teaching \& Literature ISSN 1414-3320 (Print), ISSN 2502-4914 (Online)

Vol. 18 No.2; December 2018

Copyright $\odot$ Soegijapranata Catholic University, Indonesia

The Quest for Critical Thinking Framework in ELT

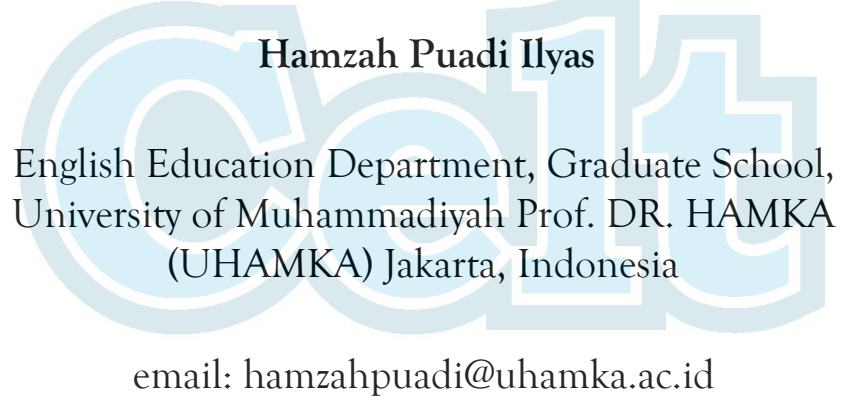

Received: 20-09-2016

Accepted: 14-09-2018

Published: 25-12-2018 


\title{
The Quest for Critical Thinking Framework in ELT
}

\author{
Hamzah Puadi Ilyas \\ hamzahpuadi@uhamka.ac.id \\ English Education Department, Graduate School, University \\ of Muhammadiyah Prof. DR. HAMKA (UHAMKA) Jakarta, \\ Indonesia
}

\begin{abstract}
Even though some authors argue that critical thinking (CT) is almost impossible to be taught to students in non-Western countries since Western and non-Western countries have different cultural background, several studies on CT conducted in Asia, Africa and predominantly Muslim countries have showed that it can be taught to non-Western students. CT has actually been fashionable in non-Western countries, and several non-Western countries have nowadays included it in their educational agenda. In spite of CT's gaining popularity in non-Western countries, there is very little information as regards what kind of CT which is adopted in those non-Western countries' education and what CT framework which can work in their teachinglearning processes, especially in the field of ELT. This article attempts to propose a critical thinking framework that can be used in ELT as well as other school subjects. The framework is the result of critically analyzing, examining and synthesizing 20 critical thinking taxonomies, strategies, programs and tests.
\end{abstract}

Key words: critical thinking framework, critical thinking in ELT, critical thinking strategies, critical thinking programs

Abstrak: Meskipun beberapa penulis beranggapan bahwa critical thinking (CT) atau berpikir kritis hamper tidak mungkin diajarkan kepada siswa di negara non Barat karena Barat dan non Barat memiliki latar belakang budaya yang berbeda, beberapa studi 
tentang CT yang diadakan di Asia, Afrika dan negara-negara yang didominasi Muslim menunjukan bahwa CT dapat diajarkan kepada siswa non Barat. Pada kenyataannya CT telah popular di negara-negara non Barat, dan banyak negara-negara tersebut telah memasukan CT ke dalam agenda pendidikan mereka. Namun, meskipun CT semakin populer di pendidikan negara-negara non Barat, sedikit sekali informasi tentang CT seperti apa yang di adopsi di negara-negara non Barat dan kerangka CT seperti apa yang bisa berhasil dalam proses pembelajaran, khususnya dalam bidang pembelajaran bahasa Inggris (ELT). Artikel ini mengusulkan kerangka CT yang dapat digunakan di ELT, juga mata pelajaran lain di sekolah. Kerangka tersebut merupakan hasil dari analisa, pemikiran, dan sintesa 20 taksonomi, strategi, program dan tes tentang berpikir kritis.

Kata kunci: kerangka berpikir kritis, berpikir kritis dalam pengajaran bahasa Inggris, strategi berpikir kritis, program berpikir kritis.

\section{INTRODUCTION}

Indonesia has included critical thinking (CT) in its education. It has been written in the government document (Regulation of the Republic of Indonesia, Number 17 Year 2010 Regarding Educational Management and Administration) as an educational objective in all levels of education. With regard to secondary education, the document (Article 77 Numbers a, b, c and d) writes "secondary education aims to produce pupils who are (a) faithful to God, morally correct, and noble, (b) knowledgeable, skilful, critical, creative, and innovative, (c) healthy, independent and confident, and (d) tolerant, socially sensitive, democratic and responsible." The appendix of the document informs that the word 'critical' means CT.

In the non-Western world, CT has also been very popular at the level of educational policy development where countries seem keen to incorporate CT into their educational agenda. However, there is very little information on CT implementation in the countries' educational sectors, including in the field of English Language Teaching (ELT). There is a gap between policy statements and actual practice in those non-Western countries. Therefore, there is a need to generate a CT framework that can be used in education, especially in ELT. 
312 Celt: A Journal of Culture, English Language Teaching \& Literature, Volume 18, Number 2, December 2018, pp. 310 - 332

There are at least two advantages by incorporating CT in ELT. First, students can learn critical thinking, and second, they can improve English language proficiency. This article proposes a CT framework that can be integrated into ELT.

\section{CT ACROSS CULTURES}

Recently, many non-Western countries have begun to include CT in their educational agendas; however, literature has emerged that offers contradictory views about integrating CT into ELT. The term ELT here refers to the teaching of English as a second or foreign language in non-Western countries. A few authors are against the infusion of CT into ELT since, according to scholars, Western and non-Western culture is different. An example for this is Atkinson's (1997), but the majority as shown by Beaumont (2010), Benesch (1999), Davidson (1998), Gieve (1998), Halvorsen (2009), Hawkins (1998), Kubota (1999), Liaw (2007), Pally (1997), and Thompson (2002) are for its inclusion. The following are details of their arguments.

Atkinson (1997) states that native speakers and non-native speakers of English have different ways of thinking; therefore, it is difficult for non-native English speakers to accept the teachings of CT. He argues by asking the question "how might individuals from cultural systems that manifestly differ from mainstream U.S. culture respond to and benefit from thinking skills instruction?" (p.79). Authors such as Davidson (1998), Hawkins (1998), and Kubota (1999) argue this proposition. Davidson (1998), for example, informs that there were presenters from such countries as Malaysia, Singapore and the Philippines who reported that they included CT in their teaching while at the Seventh International Conference on Thinking in Singapore in June 1997. This shows CT has been practiced in education in those countries. Kubota (1999) argues that the literature in applied linguistics often misleadingly described the Asian students, especially Japanese students, as passive and uncreative, while many studies on the Japanese schools, according to her, showed the opposite. In a more extreme view, Hawkins (1998) argues that not providing access to CT means preventing English language learners from success.

Some studies on CT in education conducted in non-Western countries have also showed that it is not impossible to teach CT to non-Western students. In South Korea, Shin, Lee, and Ha (2006) conducted a study to understand and compare dispositions toward CT in nursing students by 
adopting a longitudinal inquiry at a baccalaureate university programme between 1999 and 2002. There were 32 students who participated four times in completing a questionnaire. The study used the 'California Critical Thinking Disposition Inventory' (CCTDI) to measure students' CT disposition, and it reported that there was a statistically significant improvement in CT disposition of the participants.

In Turkey, Korkmaz \& Karakus (2009) carried out an experiment with a group of high school students in a Geography course. One of the research questions was to find out whether blended learning change students' CT dispositions. In the study, the control group was taught using a traditional teacher-centered and lecturing approach with question and answer sessions, while the experimental group was taught through a website with various visuals and animations in a computer lab with one computer for each student. The students were assigned activities on the website outside of the classroom and were asked to deliver their assignments via the instructor's e-mail. CCTDI was used to measure the students' CT disposition. The study showed that a blended learning model can contribute to CT disposition.

In Kuwait, Al-Fadhli \& Khalfan (2009) conducted a study to discover the impact of e-learning models on improving CT. There were 45 students in the e-learning groups and 32 in the traditional (control) groups. While the control groups were taught in a traditional manner with lecturing as the main teaching activity, the e-learning groups were taught using an e-learning model with several two-way interactive activities. The result showed that the e-learning groups scored higher than the traditional group, not only in the mean score but also in the five CT skills, namely, analysis, evaluation, inference, inductive and deductive reasoning.

Seeing the importance of CT, some non-Western countries have issued educational policies in regard to CT. For example, The South African Department of Education (DoE) released a new curriculum known as Outcomes Based Education (OBE) in 1997. According to Braund, Scholtz, Sadeck, \& Koopman (2013), OBE actually emphasizes "cooperation, CT and social responsibility, thus enabling individual learners to participate in all aspects of society" (p. 175). In 2006, the DoE introduced a new curriculum for South African schools in grades 10-12. Similar to OBE, this curriculum's emphasis was on developing students' critical and creative thinking skills and abilities (Lubben, Sadeck, Scholtz, \& Braund, 2010). 
314 Celt: A Journal of Culture, English Language Teaching \& Literature, Volume 18, Number 2, December 2018, pp. 310 - 332

The People's Republic of China has also started to incorporate CT in their education. According to Richmond (2007), China's governmental agencies support the use of the case study method in teaching learning processes, which could encourage students' CT. Also, China has included a CT section in its English textbooks for university students. For example, 'New Standard College English', a series of English textbooks edited by Simon Greenall and Mary Tomalin, contains 'Developing CT' sections in each unit.

Malaysia is reported to have adopted CT by introducing a 'Smart School Programme' (Richmond, 2007). Salih (2010) reports that Malaysia's Curriculum Development Centre has constructed a conceptual framework entitled 'Thinking Skill Thinking Strategy' with the purpose of infusing CT into school subjects. Shakir (2009) reports that the Minister of Higher Education of Malaysia has asked universities in the country to introduce soft skills, one of which is CT.

Singapore is also very serious in promoting CT. Richmond (2007) reports that Goh Chok Tong, the Singaporean Prime Minister, announced a new programme called 'Thinking Schools, Learning Nation' (TSLN). This programme focuses on creative thinking and learning skills. According to Baildon \& Sim (2009), 'Thinking Schools' means educational institutions in Singapore can produce citizens who have an ability to think critically and creatively, "while 'Learning Nation' emphasizes that the culture of thinking and lifelong learning should be high on the educational agenda" (p. 407).

All in all, even though a few authors argue that the inclusion of CT is impossible in ELT, many studies on the integration of CT in ELT in nonWestern countries have shown positive results: non-Western students' CT skills can be improved and CT can be infused in ELT. This can be inferred that the infusion of CT in ELT has two advantages: promoting ELT students' $\mathrm{CT}$ and at the same time improving their English.

\section{METHODOLOGY FOR SEARCHING THE FRAMEWORK}

There were some stages conducted in order to generate a CT framework which can be used in education, especially in ELT. Firstly, CT concepts (taxonomies, strategies, programs, and tests) were collected and collated. Then they were meticulously examined and analyzed to find key ideas. Thirdly, the entirety of the key ideas was re-examined to establish a new CT framework. All 
the CT concepts which belong to taxonomies, strategies, programs, and tests, are explained below.

\section{A. Critical thinking taxonomies}

Two taxonomies, Bloom's and Freeman's taxonomies, were reviewed and examined. Bloom's renowned taxonomy appeared in 1956 and was acclaimed as a tool to classify intended behaviours with regard to mental acts as a result of educational experiences (Moseley, Baumfield, Elliot, Gregson, Higgins, Miller, Newton, 2005). Bloom's taxonomy consists of six categories, starting from 'knowledge' as the lowest stage to the next stages such as 'comprehension,' 'application, 'analysis,' 'synthesis' and 'evaluation.' According to Bloom (as cited in Moseley et al., 2005) each category needs the skills from the lower category. For example, the 'application' category needs the skills and abilities of 'comprehension'. Similarly, 'evaluation,' which is the highest stage in the taxonomy, demands the skills and abilities of 'synthesis.'

There is, however, some criticism of Bloom's taxonomy. Wood (as cited in Moseley et al., 2005) found that it was difficult for teachers to differentiate between two CT categories: analysis and evaluation. Moseley et al. also report that many authors have criticised the 'evaluation' category as the highest stage. That is why Ormell (as cited in Moseley et al., 2015) proposes that the categories should be considered parallel, not hierarchical.

The difficulty found by teachers to differentiate categories in Bloom's taxonomy may be because it is too general, and there is no clear example of its application. Although in 1977, Hannah \& Michaelis (as cited in Moseley et al., 2015) provided a list of verbs for each category, the verbs can have various interpretation. Besides this, there are some similar verbs in different categories. For example, the verb 'compare' can be found in the categories of analysis and evaluation, 'conclude' in synthesis and evaluation, and 'summarise' in synthesis and evaluation. There is no explanation how 'compare' is applied in the process of analysis and/or evaluation. Similarly, there is no example how 'conclude' in synthesis can be different from 'conclude' in the evaluation stage.

Another criticism of the verbs attached to each category is that some verbs may not promote CT. The verbs 'tell' and 'write' under the category of synthesis may not really promote CT if students are only asked to tell and write about their personal information, for example in the context of ELT. Similarly, the verb 'imagine' falling into the category of synthesis might not encourage students' CT skills. Because it generates various interpretation, Bloom's 
316 Celt: A Journal of Culture, English Language Teaching \& Literature, Volume 18, Number 2, December 2018, pp. 310 - 332

taxonomy and the verbs attached to each category requires clear examples of implementation.

Freeman (2014) conducted a study to investigate the types of questions and tasks of EFL (English as a Foreign Language) textbooks' reading texts. In her study, she used Bloom's, Sanders', Barret's, Nuttal's, and Day \& Park's taxonomies, some of which, according to her, were not targeted at reading in a second or foreign language. Sanders' taxonomy, according to Freeman (2014), is the results of an interpretation of Bloom's taxonomy, and Bloom's and Sanders' taxonomies inspired Barret's taxonomy. While Nuttal's taxonomy imitates that of Barret, Day and Park's taxonomy "closely resembles Nuttal's" (Freeman, 2014, p. 76). This shows that Bloom's taxonomy is the basis of various taxonomies and can be interpreted in various perspectives.

Freeman's taxonomy consists of three categories: content questions, language questions and affect questions. Content questions consist of three comprehension question types: textually explicit, textually implicit and inferential comprehension. Language questions also consist of three comprehension question types: reorganization, lexical and form. Affect questions comprise two comprehension question types: personal responses and evaluation.

As mentioned, Freeman's taxonomy is the result of selecting elements of Bloom's, Sanders', Barret's, Nuttal's, and Day \& Park's taxonomies. Each taxonomy, according to Freeman, is the result of interpretation and adaptation of the previous one with Bloom's taxonomy acting as the starting point. It can be concluded that Freeman's taxonomy is also the result of interpretation and adaptation of Bloom's taxonomy. It is therefore proposed here to combine both Bloom's and Freeman's taxonomies and to examine them to find their key ideas.

\section{B. Critical thinking strategies}

Six empirical studies on infusing CT into ELT (EFL/ESL) were reviewed and examined. The six empirical studies reviewed (Dantas-Whitney, 2002; Daud \& Husin, 2004; Davidson \& Dunham, 1997; Park, 2011; Shahini \& Riazi, 2011; Yang \& Gamble, 2013) were conducted in Iran, Taiwan, South Korea, Japan and Malaysia, as well as one conducted in the USA with the participants coming from mostly Asian countries: Japan, Thailand, Taiwan, South Korea, Kuwait, Indonesia and Mongolia (Dantas-Whitney, 2002). The strategies of each study were examined to generate key ideas. 
The study by Dantas-Whitney (2002) infused critical reflection - a term which is closely associated with CT - into an ESL (English as a Second Language) classroom at a large university in the USA. Reflective audiotaped journals were used as a tool for critical reflection, and two questions were posed: (1) How do students use audiotaped journals to integrate personal perspectives into the consideration of course content? and (2) How do students perceive audiotaped journals as a tool for language learning? Dantas-Whitney's (2002) analysis produced three themes (relevance, CT, multiple identities) in regard to the first research question and one theme related to the second research question, namely that "students perceived the audiotaped journals as valuable opportunities for oral language practice, non-threatening corrective feedback and self-evaluation" (p. 548). Regarding the CT theme, DantasWhitney showed three excerpts reflecting students' CT responses. One participant expressed his critical thought addressing drugs while another participant criticized the influence of mass media on women's self-image. Unfortunately, Dantas-Whitney did not provide the number of audiotaped journals showing the participants' engagement in critical and reflective thinking. She states, "the audiotaped journals in this study encourage many of the students to engage in critical and reflective thinking" (p. 549). However, the excerpts showing critical and reflective thinking that were provided in the article show that CT can be promoted in the EFL classroom.

Daud \& Husin (2004) investigated the use of a literary text combined with concordance, a software installed on a computer to access language from a corpus, to develop ESL students' CT abilities. The study used Othello, which was chosen, according to them, as it introduced multiculturalism and human relations. While the participants in the experimental group $(n=21)$ were allowed to use the computer concordance to analyse Othello, the control group ( $n=19)$ was given traditional instruction in which the blackboard, students' notes and textbooks were used. Through classroom observation, they report that the lesson sparked a lively discussion in the two groups. The statistical results, based on the 'Cornell Critical Thinking Test', showed that even though there was a difference between the experimental and control groups in terms of their CT abilities, in general both groups showed improvement. The study shows that ELT, along with literature, can be used as a vehicle to teach CT, and non-Western students' CT skills may be enhanced.

Davidson \& Dunham (1997) also used CT in a content-based EFL programme in Japan in a study in which they attempted to find if English learners exposed to CT skills training would do significantly better than similar those without such training. The 'Ennis-Weir Critical Thinking Essay Test' 
318 Celt: A Journal of Culture, English Language Teaching \& Literature, Volume 18, Number 2, December 2018, pp. 310 - 332

(EWCTET) was used to measure Japanese students' progress in CT after experiencing intensive academic English instruction for one year. While the control group $(n=19)$ received only content-based intensive instruction, the treatment group $(n=17)$ was given additional training in CT based on Norris and Ennis's list of CT skills. The result showed that the treatment group (mean score $=6.6$ ) outperformed the control group (mean score $=0.6$ ) on EWCTET.

A study by Park (2011) explored critical reading using news articles conducted in a university classroom in South Korea. There were 38 participants who were all students majoring in English education. The critical literacy lesson was given and audio-recorded, and was included in a reading course which integrated speaking, listening and writing. After reading the texts, the students participated in discussion about the issue of social equality, wrote a response paper to promote "CT as well as measure students' achievement in the class" (Park, 2011, p. 29) and presented an article of their choice. Based on the findings of the study, Park (2011) reported that "the reaction papers collected at the end of the class revealed students' increasing command of the use of key terms to support their arguments. They were able to manipulate the language used in the text to meet their own agenda" (p. 42).

Shahini \& Riazi (2011) conducted a study on Philosophy-Based Language Teaching (PBLT) in an EFL classroom in Iran to assess the development of students' speaking, writing and thinking skills. They were motivated by literature showing that PBLT could enhance students' communication skills and thinking abilities in the L1 setting. The participants were university students in Iran majoring in engineering, sciences and humanities with the same English proficiency levels. The PBLT approaches such as asking alternative views, clarifications and reasons were introduced to the experimental group, while the control group was exposed to ordinary or non-philosophical questions. The statistical data showed that there was significant difference between the experimental and control groups in speaking ( mean difference $=5.35$ ) and writing (mean difference $=9.82$ ). This study demonstrates that PBLT may be a potential tool to promote students' CT skills in an ELT context as it helps students to respect viewpoints, explain concepts, apply reflective thinking and be critical on an issue.

Yang \& Gamble (2013) carried out an experiment by designing a course for CT-integrated EFL instruction at a university in Taiwan. The study intended to find out whether the course they designed helped the experimental group to perform better than the control group in terms of 
English proficiency, CT and academic achievement. The study reported that students in the experimental group $(n=31)$ were guided in CT activities such as information literacy and critical reading (reading), critical reflection/sharing, article critique/peer feedback, debate (listening/speaking), argumentative writing and peer critique with an emphasis on CT skills (writing), while the control group $(n=37)$ was taught effective language learning by following the textbook without emphasizing CT activities. To check students' CT skills, the students wrote an essay about global warming which was analyzed using the 'Holistic Critical Thinking Scoring Rubric' (HCTSR). Quantitative data revealed that the experimental group significantly outperformed the control group both in overall English proficiency and in CT skills.

\section{Critical thinking programs}

The existing literature proposes several CT programs that were designed by relevant scholars and authorities. They include: Philosophy for Children (P4C), Taxonomy of Socratic Questions (TSQ), Cognitive Acceleration (CA), Feuerstein's Instrumental Enrichment (FIE), Top Ten Thinking Tactics (TTTT), De Bono's CoRT programme (CoRT), Swartz and Park's Thinking Skills Taxonomy (SPTST), Six Thinking Hats (STH) and Fisher's Story-Based Activities (FSBA). Studies adopting those critical thinking programs have been conducted, and many authors (e.g. Aubrey, Ghent, \& Kanira, 2012; Green, 2009; Jenkins \& Lyle, 2010; Lam, 2012; Mills-Bayne, 2009; Reznitskaya, Glina, Carolan, Michaud, Rogers, \& Sequeira, 2012; Stanley, 2007; Thwaites, 2005; Trickey \& Topping, 2004; Vansieleghem, 2006) are the proponents of $\mathrm{P} 4 \mathrm{C}$ and CA in promoting pupils' CT skills.

Matthew Lipman created P4C due to his concern for college students' low level of thinking skills in his philosophy class (Glevey, 2006). P4C consists of eight novels designed for children aged 3-16 years old. Fisher (2008) reports that the teacher's manual consists of discussion plans consisting of "questions around a central concept or problem" (p. 23). Fisher also goes on to say that the series of questions follow Socratic questions. As it is claimed that P4C adopts Socratic questions, the questions need reviewing. One of the CT authorities to have interpreted Socratic questions is Richard Paul. Paul (1990) argues "Socratic questions, wherein students' thought is elicited and probed, allows students to develop and evaluate their thinking by making it explicit" (p. 269). Therefore, Paul's (1990) interpretation of Socratic questions was reviewed and examined. 
320 Celt: A Journal of Culture, English Language Teaching \& Literature, Volume 18, Number 2, December 2018, pp. 310 - 332

With regard to $\mathrm{CA}$, three programs for school children have been developed: CASE (Cognitive Acceleration through Science Education), CAME (Cognitive Acceleration through Mathematics Education) and CAA (Cognitive Acceleration through the Arts). Regarding Feuerstein's Instrumental Enrichment (FIE) CT programme, FIE - according to its creator Feuerstein (as cited in Glevey, 2006) - aims to "change the overall cognitive structure of the retarded performer by transforming his passive and dependent cognitive style into that characteristic of an autonomous and independent thinker" (p. 75).

TTTT, according to McGregor (2007), aims "to help students become more effective learners" (p. 111). In line with its name, this programme proposes ten tactics that are believed to be able to engage students in CT activities. Some tactics include 'comparing and contrasting,' 'getting the point,' and 'pinpointing the problem.' On the other hand, CoRT, which stands for Cognitive Research Trust, was created for younger high school students (McGregor, 2007); the programs consist of six themes, for example, 'organisation,' 'interaction,' 'creativity' and 'action'.

SPTST, according to McGregor (2007), is the basis for the development of two other CT programs, namely Activating Children Thinking (ACTs I) and Sustaining Children's Thinking (ACTs II). Those two thinking programs aim to infuse thinking across the curriculum to make students become better thinkers (McGregor, 2007). Similarly, STH, which was created by Edward de Bono, aims "to enable the learners to think in different ways rather than engaging in several different types of thinking simultaneously" (McGregor, 2007, p. 140). There are six hats of different colours that represent the direction of thinking and focus questions.

Finally, Fisher (2008) proposes story-based activities (FSBA) to promote CT. He states that stories have elements of narrative constructions that are open to reflection, interpretation and discussion and have "a context for critical thinking and discussion on issues of importance" (p. 76). The elements of narrative constructions proposed by Fisher (2008) include 'contexts', 'temporal order', 'particular events', 'intentions', 'choices', 'meanings' and 'the telling.'

\section{Critical thinking tests}

As access to commercial CT tests is limited, the review and examination are restricted to the available materials the existing literature includes and the sample tests. The CT tests reviewed and examined include the Watson-Glaser CT Appraisal (WGCTA), the Ennis-Weir CT Essay Test (EWCTET), The 
California CT Disposition Inventory (CCTDI) and The California CT Skills Test (CCTST).

The WGCTA was used by Hashemi and Ghanizadeh (2012), who carried out an experimental study on critical discourse analysis (CDA) and CT in Iranian EFL. They describe the WGCTA as having 80 test items in five subtests: interference, recognizing unstated assumptions, deduction, interpretation and evaluation of arguments. For example, recognizing unstated assumptions, which starts from test item numbers 17-32, is described as "recognizing unstated assumptions or presuppositions in given statement or assertion” (Hashemi \& Ghanizadeh, 2012, p. 40).

The EWCTET was used by Davidson and Dunham (1997). They explain that there are eight paragraphs with each paragraph illustrating a skill. Paragraph 1, for example, states 'noticing misuse of analogy and/or shift in meaning,' indicating that the paragraph requires clarity. Paragraphs $2-5$ talk about irrelevant/relevant reasoning, defective reasoning and the lack of a reason. Those four paragraphs clearly deal with reasons. Paragraph seven also talks about the idea of clarity as the skill states 'recognizing equivocation and/or the use of an arbitrary definition.' The other two paragraphs are about insufficient sampling and the credibility of expert testimony. It can be concluded that the two key ideas contained in EWCTET used to assess critical thinking are 'clarity' and 'reason'.

The CCTDI "is specifically designed to measure the disposition to engage problems and make decisions using critical thinking" (http://www.insightassessment.com). The official website also mentions that CCTDI asks test takers to respond to their agreement or disagreement with statements that express beliefs, opinions, expectations, perceptions and values. The CCTST also explores analysis, inference, evaluation, deduction and induction (Clemson University). The website from Clemson University also says that analysis involves identifying assumptions, reasons and claims. While inference skills enable respondents to make conclusions from reasons and evidence, inductive and deductive reasoning deal with drawing inferences.

\section{RESULTS}

The first level of Bloom's taxonomy, knowledge, only requires students to recall and remember information. This does not encourage students' CT skills. In the same manner, the first comprehension question type, textually 
322 Celt: A Journal of Culture, English Language Teaching \& Literature, Volume 18, Number 2, December 2018, pp. 310 - 332

explicit, of Freeman's taxonomy does not promote CT because "in this question type the answer to the question can be found stated directly in the text" (Freeman, 2014, p. 83).

Textually implicit, which is the second comprehension question type of Freeman's taxonomy, is likely to show the possibility of promoting CT as, according to Freeman (2014), "in this question type the answer to the question is stated directly in the text but is not expressed in the same language as the question" (p. 83). However, the example of this question type is not provided. The third type of Freeman's first category, inferential comprehension, is clear enough though there are also no examples provided. She states that this type of question asks students "to combine their background knowledge with the information in the text and make necessary connections" (p. 83). This activity may require students to present their 'viewpoint,' or 'perspective'. This seems similar to the second category of Bloom's taxonomy, comprehension, in which students are asked to understand the problems, state the problems using their own words and establish relationships between dates, principles, generalizations or values. The activities, to a certain degree, require students to 'summarise' and present their 'viewpoint.' Sample example verbs such as 'predict' and 'give example' attached to the comprehension category proposed by Hannah \& Michaelis can support the activities. Giving an example is necessary when students need to 'clarify' their viewpoint in, for example, stating the problems using their own words, as suggested in Bloom's taxonomy.

The second and third question types, lexical and form, seem to be able to encourage CT. Lexical question types, for example, ask learners to guess the meaning of a word or phrase from the context. To a certain degree, this requires them to make an 'assumption.' On the other hand, form questions ask students "to focus specifically on grammar and form, not information" (Freeman, 2014, p. 83). The example of activity proposed by Freeman is asking students to explain the use of one tense rather than another. This activity requires students to give 'reasons' to support their opinion or 'viewpoint.'

Affect questions, the last category of Freeman's taxonomy, consist of two comprehension question types: personal response and evaluation. This category can be associated with the last category of Bloom's taxonomy, which is also named 'evaluation.' The examination of Bloom's and Freeman's taxonomies shows that this category may promote CT.

The above mentioned empirical studies dealing with infusing CT into ELT is now followed by an examination of each study's CT strategies, with a 
view to obtaining key ideas from them. First of all, Dantas-Whitney's audiotaped journal assignment consisted of five main points. Examining the points, there are several key ideas that emerge such as summary (summarise information), reflection (relate the information to a personal experience, or the experience of someone you know), perspective (compare what you have learned to the situation in your country), prediction (talking about how this information can help you in the future), and viewpoint (other related areas that interest you). In short, the key ideas of Dantas-Whitney's critical thinking strategies are 'summary,' 'reflection,' 'perspective,' 'prediction' and 'viewpoint.'

The key ideas of Dantas-Whitey's CT strategies are in line with the taxonomies reviewed above. Summary, for example, is also found in the list of verbs of Bloom's taxonomy, namely comprehension, synthesis and evaluation categories. As has been mentioned, a criticism of Bloom's taxonomy and its list of verbs for each category is that it does not provide explicit examples, so many teachers are confused how to use 'summary' for comprehension, synthesis and evaluation. On the other hand, summary in Dantas-Whitney CT strategies is very clear in that it asks students to summarize the information they have learned about the topic (from textbooks, radio interviews, classmates' presentations and discussions, videos and outside speakers). It can be inferred that Dantas-Whitney's CT strategies clarify the taxonomies. With regard to viewpoint or perspective, Dantas-Whitney critical thinking strategies explicitly ask students to discuss their perspective on the topic by discussing their opinion, relating the information to a personal experience, comparing what they have learned and mentioning other related areas. This is similar to Freeman's taxonomy, inferential comprehension, which asks students "to combine their background knowledge with the information in the text" (Freeman, 2014, p. 83).

An examination of Daud \& Husin's descriptions of lessons conveys four key ideas. When seeing an assignment such as 'Describe the different representation and meaning of 'love' in different contexts,' it may be inferred that the prompt asks the student to clarify meaning in various perspectives. The statement 'Analyze the words based on occurrences, meanings in different contexts, the identity of the character using them, the person they refer to and the reason for using them' also gives an idea of perspective and reason. Reason and perspective also appear in the statement 'Analyze the words based on occurrence, meanings in different contexts, the identity of character using them, the person they refer to and the reason for using them.' Evidence can be found in the statement 'Based on the words, justify whether Othello is a cold- 
324 Celt: A Journal of Culture, English Language Teaching \& Literature, Volume 18, Number 2, December 2018, pp. 310 - 332

blooded murderer.' Therefore, the key ideas in the critical thinking strategies used by Daud \& Husin are 'clarity,' 'perspective,' 'reason' and 'evidence.'

Examining Norris \& Ennis's list of critical thinking skills as adopted by Davidson and Dunham conveys key ideas such as 'clarity,' 'evidence' and 'assumption.' Clarity comes from 'Elementary clarification, e.g. asking and answering questions that clarify and challenge.' Evidence is from 'Basic support such as making and judging observations,' and 'Inference, for example, making and judging deductions/ inductions.' And, 'Advanced clarification, e.g. identifying assumptions' gives an idea of 'clarity' and 'assumption.'

The examination of Park's critical engagement strategies, especially the post-reading stage, shows emerging key ideas such as 'viewpoint' (compare and contrast opinion), 'reason' (determine the reliability of data source supported by cultural and personal experience), and 'evidence' (determine text' propaganda and bias; determining the decision authors make).

Shahini \& Riazi's PBLT strategies clearly show key ideas which include 'clarity' (questions for clarity), 'disagreement' (questions for exploring disagreement), 'alternative' (questions for considering alternatives), 'viewpoint' (e.g. According to what criteria do you say that? Is this case basically the same as that?), and 'conclusion' (questions for jumping to a conclusion).

The examination of Yang \& Gamble's instructional procedures for the experimental group centers only on 'Focus on critical thinking' parts, which show several key ideas. For example, 'Identification of "information need"' may refer to prediction. Evidence, viewpoint and perspective can be derived from the statements 'Recognizing bias, use of supporting data, and diversity of opinion,' 'Critical analysis of information sources,' and 'Evaluate claim and evidence from three authentic, self-selected articles.' Therefore, the key ideas obtained from Yang and Gamble's strategies are 'prediction,' 'evidence,' 'viewpoint' and 'perspective.'

The key ideas of CT strategies above clarify, or even complement the taxonomies, especially Bloom's taxonomy, which lacks explicit application. As mentioned, Dantas-Whitney's summary can be used as an example of what a teacher can do in dealing with the categories of Bloom's taxonomy. Other strategies such as prediction, reason and evidence fit the taxonomies. While prediction is listed in the list of verbs of Bloom's taxonomy, reason and evidence are in agreement with Freeman's taxonomy, personal response 
category, in which the students are required to provide a rationale and justification for their view, as has been mentioned above.

The examination of critical thinking programs above has generated some key ideas. The Socrates questioning shows six key ideas of asking critical thinking questions and consists of questions asking for 'clarification,' 'assumptions,' 'evidence,' 'viewpoints or perspectives,' 'implications and consequences' and 'question.' With regard to CA, the first part of CA, setting the thinking agenda, consists of questions that convey the ideas of the questioning viewpoint (what do you think?), reason (do you have a reason?), perspective (is there another way?) and prediction (what do you think happens next?). The second part, developing responses, poses some questions regarding reason (what reasons do you have for saying that?), agreement and disagreement (why do you disagree/agree?), clarification (what do you mean by that?) and alternative (are there any alternatives?). The third part consists of questions asking for clarity (are you saying that...?), assumption (so far your point of view...am I correct in assuming that you think...?), summary (can you sum up your arguments/ideas/views?), prediction (what do you predict will happen next?), and implication (the implications of what you have said are...). Therefore, the key ideas that emerge from CA are 'viewpoint,' 'reason,' 'perspective,' 'prediction,' 'agreement,' 'disagreement,' 'clarity,' 'alternative,' 'assumption,' 'summary' and 'implication.' These key ideas support Paul's Socratic questioning.

The examination of FIE focuses on the 'improved performance' column, as the ten activities listed in the column are actually what the critical thinking processes in the other column expect. The activities deal with making conclusion (confidence in drawing accurate conclusions; can draw accurate conclusions from events or data), promoting perspective (can project relationship among broader, complex concepts; sees problem situations and takes initiative to solve; understand cause and effect.), exploring alternative and judging consequence (stop to think before acting; explores alternatives; assesses consequences), seeking clarification and understanding implication (can organize and integrate bits of information into meaningful system; seeks clarification of instructions; understand implicit instructions). It is therefore inferred that the key ideas of FIE are 'conclusion,' 'perspective,' 'alternative,' 'consequence,' 'clarification' and 'implication.'

Examining the ten activities listed in TTTT generates the key ideas. For example, the first and fifth tactics (pinpointing the problem - clarifying what the problem is; correct communication - making your instructions as clear as 
possible) indicate clarification. Other tactics mostly refer to perspective (systematic search - going beyond scanning of material, continuing to look at the data; planning - paying selective attention to relevant information; check and change - trying new ideas when solution is not working; comparing and contrasting - seeing similarities and differences; getting the point - shifting confusing information for relevant and irrelevant material; using several sources - thinking about more than one piece of information). It is concluded that the two key ideas found in TTTT are 'clarification' and 'perspective.'

Seven key ideas emerge as a result of examining the six themes contained in the CoRT. The first and fourth themes (to broaden perception; to develop effective new ideas) show perspective. The second theme (basic thinking operations, i.e.: when to use 'analyze,' 'compare,' 'conclude,' etc.) contains an element of conclusion. The third theme (intended to be interactive, constructive argument: examining both sides, evidence, agreement, disagreement, irrelevance, outcomes) talks about perspective, evidence, agreement and disagreement. The fourth theme, i.e. to develop effective new ideas, clearly refers to perspective. Finally, the fifth theme (information, questions, guessing, belief, values and clarification) contains the elements of question and clarification. The seven key ideas from CoRT, therefore, deal with encouraging 'perspective,' 'conclusion,' 'evidence,' 'agreement,' 'disagreement,' 'question' and 'clarification.'

Examining SPTST generates key ideas that are clearly mentioned in its CT activities such as assumptions, reasons/conclusions, conditional reasoning, reasoning by analogy and prediction. Consequence can be inferred from 'causal explanation (how does one thing affect another?).' Other activities such as 'thinking up different possibilities to reaching a solution,' 'weighing up pros and cons to inform a view or decision,' 'creating new ideas and developing a framework,' and 'model or suggestion that connects multiple pieces of information together' can be considered to be encouraging perspective. So, the six key ideas promoting critical thinking proposed by SPTST are 'assumption,' 'reason,' 'conclusion,' 'prediction,' 'consequence' and 'perspective.'

Regarding STH, the strategies corresponding with the white hat focus on questions about 'question.' The strategies with a yellow hat ask about reason. A question in the green hat explores perspective, and two questions with the blue hat can promote viewpoint. Therefore, it can be concluded that the key ideas of CT activities proposed by STH are questions exploring 'question,' 'reason,' 'perspective' and 'viewpoint.' 
An examination of example questions of FBSA posed in each element generates some key points which are mostly similar to Paul's Socratic questioning. They include clarification (e.g. What does 'once upon a time' mean?), prediction (e.g. What could have happened? What should have happened? What could/should happen next? What does X hope will happen), reason (e.g. What reasons would X give?), viewpoint (e.g. What kind of story is it? Why does $\mathrm{X}$ think that? What is the decisive moment in the story? What is the message (or moral) of the story? What did the character feel, think and believe? What did they all feel, think or believe?), alternative (e.g. What alternative choices or decisions are there?), consequence (e.g. What were the consequences?) and perspective (e.g. Could you tell this story in different ways? How would you change the characters or events?). The key ideas of FSBA are questions about 'clarity,' 'prediction,' 'reason,' 'viewpoint,' 'alternative,' 'consequence' and 'perspective.'

The examination of four critical thinking tests has generated key ideas about what they are testing. The key ideas of critical thinking tests in alphabetical order are 'agreement,' 'assumption,' 'evidence,' 'clarity,' 'conclusion,' 'disagreement' and 'reason.'

The examination of $20 \mathrm{CT}$ concepts (taxonomies, strategies, programs and tests) above has generated several key ideas. The entire list of key ideas is (in alphabetical order): agreement, alternative, assumption, evidence, clarification, conclusion, consequence, disagreement, implication, perspective, prediction, question, reason, reflection, summary and viewpoint. Critical thinking taxonomies, strategies, programs and tests share most of these ideas. For example, clarity, perspective, assumption and reason are found in all critical thinking taxonomies, strategies, programs and tests.

However, there is one key idea that is not shared by the critical thinking strategies, programs, taxonomies and tests. This idea is 'reflection'; it is only found in Dantas-Whitney's audiotaped journal assignment for writing task. As proposed by Dantas-Whitney this concept is 'relating the information to a personal experience or the experience of someone you know.' This seems to overlap with 'viewpoint' and 'perspective'. As mentioned in the previous section, Dewey states that reflective thinking means examining things, not accepting things at face value. Adopting Dewey's idea, all key ideas of these critical thinking taxonomies, strategies, programs and tests can be categorized as reflective thinking. Reflection is, therefore, omitted from the list of key ideas. 
328 Celt: A Journal of Culture, English Language Teaching \& Literature, Volume 18, Number 2, December 2018, pp. 310 - 332

Some other activities are not included in the key ideas, as they do not seem to promote critical thinking. For example, one of ten tactics in TTTT is 'setting your own target - understanding your purpose, wishes and the goals others have for you.' The idea derived from the phrase is 'achieving goals,' though it is not related to critical thinking in this context. Another is 'sequencing - ordering or ranking information' which is found in SPTST. This phrase could be a part of the process of gathering evidence. Therefore, these two phrases are not represented in the final list of key words.

This section, therefore, proposes that the textbook evaluation must be done by examining text-based questions and tasks probing/about agreement, assumption, evidence, clarity, conclusion, consequence, disagreement, implication, perspective, prediction, question, reason, reflection, summary and viewpoint. These ideas create the CT framework used education, especially in the context of ELT.

\section{CONCLUSION}

The argument claiming that CT is almost impossible in non-Western countries may be baseless. There is no single study supporting this proposition. On the other hand, some studies on CT in non-Western education, including in ELT, have shown the opposite: it is possible to teach CT to non-Western students and it is possible to incorporate CT into ELT. At least there are two advantages of infusing CT into ELT. First, non-Western students can learn how to be critical, and second, at the same time they can improve English language proficiency. The reason why non-Western students lack CT might be the educational system which has not fully supported CT, not because the students cannot be critical.

Realizing the importance of CT in this ever-globalizing world, nonWestern countries have included CT in their educational agenda. Some programs have been designed by educational authorities in those countries. So far, however, there has been little discussion about what kind of CT which can be used in education, especially in ELT. The proposed CT framework above as a result of synthesizing 20 critical thinking taxonomies, strategies, programs and tests can be used as a guide to promote ELT students' CT skill; however, the framework can also be used in other school subjects such as civics, religion, history, literature, economics, or even biology. 
ELT practitioners, especially those teaching EFL and ESL, may get benefits from this CT framework, but they also need to be critical to the framework. Finally, studies investigating the effectiveness of the framework in promoting students' CT skill need to be conducted in order to find possible additional elements of CT, and thus improving this framework.

\section{REFERENCES}

Al-Fadhli, S., \& Khalfan, A. (2009). Developing critical thinking in e-learning environment: Kuwait university as a case study. Assessment and Evaluation in Higher Education, 34(5), 529-536.

Atkinson, D. (1997). A critical approach to critical thinking in TESOL. TESOL Quarterly, 31(1), 71-94.

Aubrey, C., Ghent, K., \& Kanira, E. (2012). Enhancing thinking skills in early childhood. International Journal of Early Years Education, 20(4), 332-348.

Baildon, M. C., \& Sim, J. B. (2009). Notions of criticality: Singaporean teachers' perspectives of critical thinking in social studies. Cambridge Journal of Education, 39(4), 407-422.

Beaumont, J. (2010). A sequence of critical thinking tasks. TESOL Journal, 1(4), $427-448$.

Benesch, S. (1999). Thinking critically, thinking dialogically. TESOL Quarterly, 33(3), 573-580.

Braund, M., Scholtz, Z., Sadeck, M., \& Koopman, R. (2013). First steps in teaching argumentation: A South African study. International Journal of Educational Development, 33(2), 175-184.

Dantas-Whitney, M. (2002). Critical reflection in the second language classroom through audiotaped journals. System, 30(4), 543-555.

Daud, M. N., \& Husin, Z. (2004). Developing critical thinking skills in computer-aided extended reading classes. British Journal of Educational Technology, 35(4), 477-487. 
330 Celt: A Journal of Culture, English Language Teaching \& Literature, Volume 18, Number 2, December 2018, pp. 310 - 332

Davidson, B. W. (1998). Comments on Dwight Atkinson's "A Critical Approach to Critical Thinking in TESOL": A case for critical thinking in the English language classroom. TESOL Quarterly, 32(1), 119-123.

Davidson, B. W., \& Dunham, R. A. (1997). Assessing EFL student progress in critical thinking with the ennis-weir critical thinking essay test. JALT Journal, 19(1), 43-57.

Fisher, R. (2008). Teaching thinking: Philosophical enquiry in the classroom ( ${ }^{\text {rd }} \mathrm{ed}$.). London: Continuum.

Freeman, D. (2014). Reading comprehension questions: The distribution of different types in global EFL textbooks. In N. Hardwood (Ed.), English language teaching textbooks: Content, consumption, production (pp. 72-110). London: Palgrave Macmillan.

Gieve, S. (1998). A Reader Reacts. TESOL Quarterly, 32(1), 123-129.

Glevey, K. E. (2006). Thinking E̊ education. Leicester: Matador.

Green, L. (2009). Education for democracy: Using the classroom community of inquiry to develop habits of reflective judgement in South African schools. Thinking Skills and Creativity, 4(3), 178-184.

Halvorsen, A. (2009). Incorporating critical thinking skills development into ESL/EFL courses. Retrieved September 1, 2012, from https://learnweb.harvard.edu/ccdt/_uploads/documents/Halvorsen\%2 0-\%20Incorporating\%20Cpdf

Hawkins, M. R. (1998). Apprenticing nonnative speakers to new discourse communities. TESOL Quarterly, 32(1), 129-132.

Jenkins, P., \& Lyle, S. (2010). Enacting dialogue: The impact of promoting philosophy for children on the literate thinking of identified poor readers, aged 10. Language and Education, 24(6), 459-472.

Korkmaz, O., \& Karakus, U. (2009). The impact of blended learning model on student attitudes towards geography course and their critical thinking dispositions and levels. Turkish Online Journal of Educational Technology TOJET, 8(4), 51-63.

Kubota, R. (1999). Japanese culture constructed by discourses: Implications for applied linguistics research and ELT. TESOL Quarterly, 33(1), 9-35. 
Lam, C. (2012). Continuing Lipman's and Sharp's pioneering work on philosophy for children: Using Harry to foster critical thinking in Hong Kong students. Educational Research and Evaluation, 18(2), 187-203.

Liaw, M. L. (2007). Content-based reading and writing for critical thinking skills in an EFL context. English Teaching and Learning, 3(2), 45-87.

Lubben, F., Sadeck, M., Scholtz, Z., \& Braund, M. (2010). Gauging students' untutored ability in argumentation about experimental data: A South African case study. International Journal of Science Education, 32(16), 2143. 2166.

McGregor, D. (2007). Developing thinking; developing learning: A guide to thinking skills in education. Berkshire, England: Open University Press.

Mills-Bayne, M. (2009). A lesson in underestimating young children. Critical and Creative Thinking, 17(1), 35-41.

Moseley, D., Baumfield, V., Elliot, J., Gregson, M., Higgins, S., Miller, J., Newton, D. (2005). Frameworks for thinking: A handbook for teaching and learning. Cambridge: Cambridge University Press.

Pally, M. (1997). Critical thinking in ESL: An argument for sustained content. Journal of Second Language Writing, 6(3), 293-311.

Park, Y. (2011). Using news articles to build a critical literacy classroom in an EFL setting. TESOL Journal, 2(1), 24-51.

Paul, R. (1990). Critical thinking: What every person needs to survive in a rapidly changing world. Rohnert Park, CA: Sonoma State University.

Reznitskaya, A., Glina, M., Carolan, B., Michaud, O., Rogers, J., \& Sequeira, L. (2012). Examining transfer effects from dialogic discussions to new tasks and contexts. Contemporary Educational Psychology, 37(4), 288-306.

Richmond, J. E. D. (2007). Bringing critical thinking to the education of developing country professionals. International Education Journal, 8(1), 1 29.

Shahini, G., \& Riazi, A. (2011). A PBLT approach to teaching ESL speaking, writing, and thinking skills. ELT Journal, 65(2), 170-179. 
332 Celt: A Journal of Culture, English Language Teaching \& Literature, Volume 18, Number 2, December 2018, pp. 310 - 332

Salih, M. (2010). Developing thinking skills in Malaysian science students via an analogical task. Journal of Science and Mathematics Education in Southeast Asia, 33(1), 110-128.

Shakir, R. (2009). Soft skills at the Malaysian institutes of higher learning. Asia Pacific Education Review, 10(3), 309-315.

Shin, K., Lee, J., \& Ha, J. (2006). Critical thinking dispositions in baccalaureate nursing students. Journal of Advanced Nursing, 56(2), 182189.

Stanley, S. (2007). A skills based approach to P4C - philosophy: Fairy tales and the foundation stage. Gifted Education International, 22(2-3), 172-181.

Thompson, C. (2002). Teaching critical thinking in EAP courses in Australia. TESOL Journal, 11(4), 15-20.

Thwaites, H. (2005). Can "philosophy for children" improve teaching and learning within attainment target 2 of religious education? Education 3 . 13, 33(3), 4-8.

Trickey, S., \& Topping, J. K. (2004). "Philosophy for children": A systematic review. Research Papers in Education, 19(3), 365-380.

Vansieleghem, N. (2006). Listening to dialogue. Studies in Philosophy and Education, 25(1-2), 175-190.

Yang, Y. C., \& Gamble, J. (2013). Effective and practical critical thinkingenhanced EFL instruction. ELT Journal, 67(4), 398-412. 